\title{
In silico evaluation of some 4-(quinolin-2- yl)pyrimidin-2-amine derivatives as potent V600E-BRAF inhibitors with pharmacokinetics ADMET and drug-likeness predictions
}

\author{
Abdullahi Bello Umar, Adamu Uzairu, Gideon Adamu Shallangwa and Sani Uba
}

\begin{abstract}
Background: The resistance of V600E-BRAF to the vemurafenib and the side effects of the identified inhibitors trigger the research for a novel and more potent anti-melanoma agents. In this study, virtual docking screening along with pharmacokinetics ADMET and drug-likeness predictions were combined to evaluate some 4-(quinolin-2yl)pyrimidin-2-amine derivatives as potent V600E-BRAF inhibitors.

Results: Some of the selected compounds exhibited better binding scores and favorable interaction with the V600E-BRAF enzyme. Out of the screened compounds, two most potent (5 and 9) having good Rerank scores (128.011 and - 126.258) emerged as effective and potent V600E-BRAF inhibitors that outperformed the FDAapproved V600E-BRAF inhibitor (vemurafenib, - 118.607). Thus, the molecular docking studies revealed that the studied compounds showed competing for inhibition of V600E-BRAF with vemurafenib at the binding site and possessed better pharmacological parameters based on the drug-likeness rules filters for the oral bioavailability, and ADMET risk parameters.

Conclusion: The docking analysis, drug-likeness rules filters, and ADMET study identified compounds (5 and 9) as the best hits against V600E-BRAF kinase with enhanced pharmacological properties. This recommends that these compounds may be developed as potent anti-melanoma agents.
\end{abstract}

Keywords: Pyrimidines, V600E-BRAF, Molecular docking, ADMET

\section{Background}

The RAS/RAF/ERK/MEK signaling pathways performs a significant role in tumorigenesis and cancer progression [1]. It is generally believed that RAF kinases are the essential parts of the MAPK signaling pathways, which act downstream of the RAS and is in charge of ERK and MEK activation [2]. The unusual activation of the RAF, commonly BRAF, results in an increase in the MAPK pathway, and is

\footnotetext{
* Correspondence: abdallahbum@yahoo.com

Department of Chemistry, Faculty of Physical Sciences, Ahmad Bello University, P.M.B.1045, Zaria, Kaduna State, Nigeria
}

often seen in cancers, and contributes more to oncogenesis [3]. Pathological investigations have stated that activated patterns of the BRAF gene is existing in nearly $8 \%$ of all cancers [4] and are mostly linked with melanoma (about 66\%) [5]. What is unique is that about $90 \%$ of the identified BRAF-mutations are that of V600E mutated, which enhances the kinase activity, and concomitantly stimulates the signaling at pretty high levels [6]. Approximately one-third of human cancers possess mutations in this pathway [7], among which the mutation of V600E-BRAF has been identified in 34\% of malignant melanoma [8], $4.7 \%$ to $10 \%$ of colorectal cancer $[9,10], \sim 58 \%$ of papillary thyroid cancer

\section{Springer Open}

() The Author(s). 2020 Open Access This article is licensed under a Creative Commons Attribution 4.0 International License, which permits use, sharing, adaptation, distribution and reproduction in any medium or format, as long as you give appropriate credit to the original author(s) and the source, provide a link to the Creative Commons licence, and indicate if changes were made. The images or other third party material in this article are included in the article's Creative Commons licence, unless indicated otherwise in a credit line to the material. If material is not included in the article's Creative Commons licence and your intended use is not permitted by statutory regulation or exceeds the permitted use, you will need to obtain permission directly from the copyright holder. To view a copy of this licence, visit http://creativecommons.org/licenses/by/4.0/. 
[11], 94\% of papillary craniopharyngioma [12] 12.5\% of grade 1 serous ovarian carcinoma, and a wide variety of other cancers [13]. In this respect, V600E-BRAF has been a target of interest for therapeutic interference targeting which has confirmed to be the main improvement in the area of melanoma therapy.

Until now, several inhibitors of V600E-BRAF have been acquired, and many are at different steps of pre-clinical and clinical stage of development $[14,15]$. The most successful case is the gradual optimization for the final drug vemurafenib employing FBDD (fragment-based drug design) strategy [16]. Compared with other known drugs (Fig. 1), such as dabrafenib and sorafenib, vemurafenib has a significant advantage in the RAF kinase selectivity $[17,18]$. It exhibits a much stronger inhibitory effect toward BRAF kinase over the other two subtypes [19]. Hence, it is widely employed in the treatment of diseases caused by V600E-BRAF. Despite these successes, many patients developed resistance to vemurafenib $[20,21]$ and high rates of squamous cell carcinomas linked with identified inhibitors and keratoacanthoma (around 25\%) have been published [19, 22]. Besides, what should be notified is that the rate of melanoma has considerably improved over the past decade [23, 24]. Consequently, to defeat these shortcomings of vemurafenib and the other drugs, the search and development of new effective V600EBRAF inhibitors are significantly relevant.

In the drug discovery process, promising lead identification is accomplished by high-throughput experimental screening (HTS), but it is time-consuming and costly
[25]. Therefore, it is necessary to overcome these limitations of conventional drug identification approaches with low cost, effective, and broad-spectrum computational approaches. High-throughput virtual screening, which is extensively employed presently in pharmaceutical industry research, is a screening approach generally utilized by the medicinal chemist. The availability of a high-resolution crystal structure of the protein target as a template for computational screening increases the feasibility of virtual screening $[6,26]$. Moreover, a series of 11 4-(quinolin-2-yl)pyrimidin-2-amine derivatives was synthesized and biologically assessed against the A375P melanoma cell line lately by Lee et al. [27]. The compounds have shown excellent anti-proliferative activities against the A375P cell line. To the best search of the authors, these observations were not studied with any theoretical method. Thus, in the present study, these compounds were screened against V600E-BRAF kinase (a known melanoma target) [28] using in silico molecular docking approach to predict interactions between the compounds and the receptor, saving money and time during the method of drug filtering. Additionally, the compounds were further screened by drug-likeness rules and ADMET risk parameters.

\section{Methods}

\section{Ligand selection and optimization}

A series of 11 4-(quinolin-2-yl)pyrimidin-2-amine derivatives were retrieved from the literature [27]. The 2D<smiles>CCCS(=O)(=O)Nc1ccc(F)c(C(=O)c2c[nH]c3ncc(-c4ccc(Cl)cc4)cc23)c1F</smiles> 
chemical structures of the compounds have been drawn using ChemDraw v. 12.0. The energy of these compounds was minimized using the MM2 force field method [29] and converted to 3D format using Spartan 14 v. 1.1.4 software package from Wavefunction Inc. The geometry optimization of the compounds was performed using density functional theory (DFT) approach at the B3LYP level of theory and 6-31G** (basis set). The fully optimized structures of the compounds were saved in PDB file format for docking using Spartan 14 and then taken to Molegro Virtual Docker (MVD) [30] for docking purposes.

\section{Protein preparation and molecular docking simulation}

The 3D X-ray structure of the receptor (V600E-BRAF) attached with vemurafenib (PDB-ID: 3OG7) [31-33] was collected from the Protein Databank at (http://www. rcsb.org/). The PDB file of V600E-BRAF was prepared using Molegro Virtual Docker 6.0 [30] by updating the $\mathrm{H}$-atoms and removal of the water (excess) molecules found in the complex structure and the attached ligand (vemurafenib) was also removed from the target. The potential ligand-binding cavity of the V600E-BRAF receptor was predicted, and the binding cavity was set inside a restricted sphere of $\mathrm{X}: 1.59, \mathrm{Y}:-1.28, \mathrm{Z}:-6.21$ with a radius $28 \mathrm{~A}$ having a grid resolution of $0.30 \mathrm{~A}$.

For molecular docking, all the prepared compounds (ligands) including vemurafenib (reference inhibitor) were then imported into the Molegro Virtual Docker 6.0, and its bond flexibility was set together with the side chains of the amino acid, which was also set inside the restricted sphere. The flexibility was set with a strength of 0.90 and a tolerance of 1.10. The RMSD threshold was set as $2.00 \mathrm{~A}$ for the multiple clusters poses with 100.00 energy penalty values. The docking algorithm was set for a maximum of 1500 iteration with a simplex evolution size of 50 . The docking simulation was run for a minimum of 50 times for the 10 poses, and the best poses were chosen based on the set scoring functions such as the MolDock score, Rerank score, E-interaction, and E-H-bond [34]. Additionally, Discovery Studio (DS) Visualizer v. 3.5 was adopted to visualize various intermolecular interactions such as H-bond, hydrophobic, halo bond, and $\pi /$ aryl interactions.

\section{Prediction of pharmacokinetics ADMET and drug-likeness properties}

The application of computational tools for identifying the novel candidate drugs assist to lessen the number of experimental studies and for increasing the success rate. For this purpose, we applied some drug-likeness rules as an initial screening step for oral bioavailability and next, secondary screening was conducted by calculating the ADMET (absorption, distribution, metabolism, excretion, and toxicity) profile for a measure of pharmacokinetics parameters [35] using SwissADME (www.swissadme.ch/) online tool.

\section{Results}

From the molecular docking simulation studies of the studied compounds on V600E-BRAF, the well-known BRAF mutation (PDB ID: 3OG7)), it is revealed that these compounds were docked at the active site of the V600E-BRAF target with a favorable Rerank scores and docking scores compared to vemurafenib (Table 1). The detailed docking results and types of interactions involved are presented in Tables 1 and 2, respectively. Also, Figs. 2, 3, 4, 5, and 6, respectively, depicted the $2 \mathrm{D}$ and $3 \mathrm{D}$ binding modes of the docked compounds at the binding cavity of V600E-BRAF. The compounds with the good MolDock score $(\geq$ 158.139) and Rerank score ( $\geq-118.607)$ were identified as potential hits (having higher binding scores than vemurafenib). To further ensure that the selected compounds are the novel drugs, we utilized the drug-likeness and pharmacokinetic ADMET parameters with vemurafenib as the reference. The SwissADME (www.swissadme.ch/) online tool was used to predict in silico drug-likeness features and ADMET features the results are reported in Tables 3 and 4 respectively.

\section{Discussion}

The ability of the studied compounds to bind with the target is given in terms of MolDock and Rerank Score. The MolDock Score and Rerank scoring are used as the parameters for analyzing the docking results. The docking scores of the studied compounds are presented in Table 1 where the ability of ligand-protein interactions is ranked based on the MolDock score and Rerank score respectively. From the docking result, it is found that compounds $(5,9,10$, and 11) formed bonds and nonbond interaction at the binding pocket of the receptor as manifest from the E-interaction and E-H-bond (Table 2) and that their binding patterns (Table 3) are similar to that of the standard drug (vemurafenib), and they pose maximum MolDock Score as well as the Rerank score, indicating that the compounds had more favorable ligand-protein interaction energy than vemurafenib at the binding site of V600E-BRAF and the docked conformations of these compounds with the lowest energy were chosen for the subsequent studies.

The docked complex of compound 5 and V600EBRAF was portrayed in Fig. 2 which has a Rerank score of - 128.011 and it is bonded into V600E-BRAF binding cavity via five Hbond, one $\pi$-sulfur interaction, and three $\pi-\pi$ stacked interaction. The nitrogen atom of the amino group attached with quinoline moiety formed two H-bonds with GLU533 and CYS532 residues sequentially. Two fluorine atoms of the trifluoromethyl group also formed three hydrogen bonds with ASP594, 
Table 1 The docking results (scores) of the studied compounds with Vemurafenib as the reference

\begin{tabular}{|c|c|c|c|c|c|c|}
\hline Complex & MolDock score ${ }^{a}$ & Rerank score ${ }^{\mathrm{b}}$ & E-interaction ${ }^{c}$ & E-Hbond ${ }^{d}$ & $\mathrm{LE}^{1}$ & $\mathrm{LE}^{3}$ \\
\hline 1 & -137.788 & -108.491 & -154.195 & -2.500 & -5.103 & -4.018 \\
\hline 2 & -138.199 & -103.557 & -137.910 & -0.616 & -4.936 & -3.698 \\
\hline 3 & -143.249 & -120.404 & -163.471 & -8.473 & -4.940 & -4.152 \\
\hline 4 & -138.935 & -94.500 & -153.642 & -1.523 & -4.791 & -3.259 \\
\hline 5 & -167.246 & -128.011 & -183.969 & -8.146 & -5.575 & -4.267 \\
\hline 6 & -135.974 & -105.232 & -159.953 & -1.568 & -4.532 & -3.508 \\
\hline 7 & -133.878 & -106.025 & -158.937 & -3.538 & -4.463 & -3.534 \\
\hline 8 & -139.191 & -113.258 & -156.641 & -1.325 & -4.640 & -3.775 \\
\hline 9 & -158.484 & -126.258 & -172.123 & -6.156 & -4.802 & -3.826 \\
\hline 10 & -156.937 & -129.661 & -176.571 & -5.696 & -4.756 & -3.929 \\
\hline 11 & -165.157 & -140.478 & -194.665 & -4.850 & -5.161 & -4.390 \\
\hline Vem. & -158.139 & -118.607 & -167.952 & -4.741 & -4.792 & -3.594 \\
\hline
\end{tabular}

a Moldock score was obtained from the PLP scoring functions with a new H-bond term and extra charge schemes [30]

${ }^{b}$ Rerank score is a linear combination of E-inter (Electrostatic, Van der Waals, H-bonding, steric) between the ligand and the protein target, and E-intra.

(Electrostatic, Van der Waals, H-bonding, sp2-sp2, torsion,) of the ligand weighted by pre-defined coefficients [30]

${ }^{\mathrm{C}} \mathrm{E}$-interaction is the total energy between the protein and the pose

${ }^{\mathrm{d}} \mathrm{E}-\mathrm{Hb}$ bond is Hbond energy. $L E^{7}$ ligand efficiency-1(MolDock score/heavy atoms count), $L E^{3}$ ligand efficiency 3 (Rerank score/heavy atoms count)

Table 2 Molecular interactions present in the selected complexes and the amino acids involved

\begin{tabular}{|c|c|c|c|c|c|c|c|c|c|}
\hline Complex & Hbond & Hbond-length & Carbon-Hbond & Alkyl & Pi-Alkyl & $\mathrm{Pi}-\mathrm{Pi}$ & Pi-cation & Pi-sulfur & Halo-bond \\
\hline 5 & $\begin{array}{l}\text { LYS483 } \\
\text { ASP594 } \\
\text { GLY596 } \\
\text { CYS532 } \\
\text { GLU533 }\end{array}$ & $\begin{array}{l}2.40188 \\
2.41834 \\
2.85749 \\
2.12511 \\
3.02445\end{array}$ & $\begin{array}{l}\text { ASP594 } \\
\text { GLN530 }\end{array}$ & $\begin{array}{l}\text { ALA481 } \\
\text { ILE527 } \\
\text { LYS483 }\end{array}$ & $\begin{array}{l}\text { ALA481 } \\
\text { LEU514 } \\
\text { CYS532 } \\
\text { LYS483 } \\
\text { LEU514 }\end{array}$ & $\begin{array}{l}\text { PHE583 } \\
\text { PHE583 } \\
\text { PHE583 }\end{array}$ & LYS483 & CYS532 & ILE527 \\
\hline 9 & $\begin{array}{l}\text { LYS483 } \\
\text { ASP594 } \\
\text { GLY596 } \\
\text { CYS532 }\end{array}$ & $\begin{array}{l}2.50055 \\
2.7364 \\
2.74485 \\
2.07217\end{array}$ & $\begin{array}{l}\text { LYS483 } \\
\text { ASP594 } \\
\text { GLN530 }\end{array}$ & $\begin{array}{l}\text { LEU505 } \\
\text { ILE527 }\end{array}$ & $\begin{array}{l}\text { PHE583 } \\
\text { ALA481 } \\
\text { LEU514 } \\
\text { LYS483 }\end{array}$ & $\begin{array}{l}\text { PHE583 } \\
\text { PHE583 } \\
\text { PHE583 }\end{array}$ & & $\begin{array}{l}\text { CYS532 } \\
\text { CYS532 }\end{array}$ & ASP594 \\
\hline 10 & $\begin{array}{l}\text { LYS483 } \\
\text { ASP594 } \\
\text { ASP594 }\end{array}$ & $\begin{array}{l}2.67517 \\
2.52033 \\
1.73749\end{array}$ & $\begin{array}{l}\text { LYS483 } \\
\text { LYS483 } \\
\text { LYS483 } \\
\text { ASP594 }\end{array}$ & $\begin{array}{l}\text { ALA481 } \\
\text { LEU514 } \\
\text { VAL471 }\end{array}$ & $\begin{array}{l}\text { PHE468 } \\
\text { PHE583 } \\
\text { PHE583 } \\
\text { LYS483 } \\
\text { ILE527 } \\
\text { LEU505 } \\
\text { ILE527 } \\
\text { VAL471 } \\
\text { LEU514 }\end{array}$ & PHE595 & LYS483 & & $\begin{array}{l}\text { ASN581 } \\
\text { ASP594 } \\
\text { ASP594 }\end{array}$ \\
\hline 11 & $\begin{array}{l}\text { LYS483 } \\
\text { ASP594 } \\
\text { ASP594 }\end{array}$ & $\begin{array}{l}2.24422 \\
2.48517 \\
1.79414\end{array}$ & ASP594 & & $\begin{array}{l}\text { LYS483 } \\
\text { ILE527 } \\
\text { LEU505 } \\
\text { VAL471 } \\
\text { ALA481 } \\
\text { LYS483 } \\
\text { ALA481 }\end{array}$ & TRP531 & LYS483 & CYS532 & \\
\hline Vem. & $\begin{array}{l}\text { CYS532 } \\
\text { GLY596 } \\
\text { GLN530 }\end{array}$ & $\begin{array}{l}1.69013 \\
2.06126 \\
1.74262\end{array}$ & $\begin{array}{l}\text { ASP594 } \\
\text { GLY596 } \\
\text { CYS532 } \\
\text { THR529 }\end{array}$ & $\begin{array}{l}\text { LEU505 } \\
\text { ILE527 }\end{array}$ & $\begin{array}{l}\text { PHE595 } \\
\text { LYS483 } \\
\text { ALA481 } \\
\text { LEU514 } \\
\text { CYS532 } \\
\text { ALA481 } \\
\text { CYS532 }\end{array}$ & $\begin{array}{l}\text { TRP531 } \\
\text { PHE583 }\end{array}$ & LYS483 & & ALA481 \\
\hline
\end{tabular}




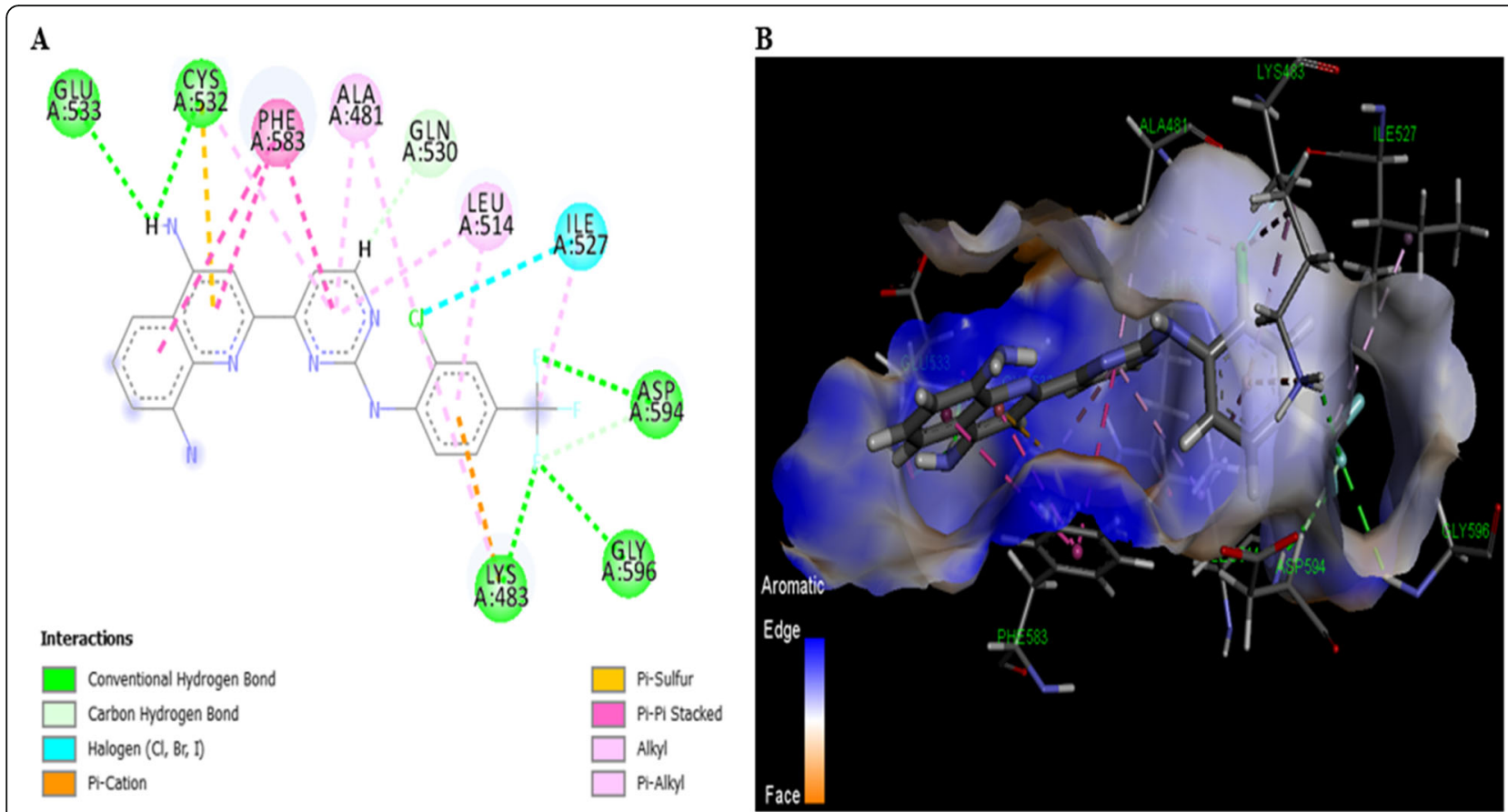

Fig. 2 a 2D diagram for the interaction of compound 5 with V600E-BRAF, b 3D view of the compound 5 in the binding site of V600E-BRAF

GLY596, and LYS483 residues, respectively. Two carbon-H-bond were also observed in the complex with ASP594 and GLN530 residues. The $\pi$-sulfur interaction was established between a ring (benzene) and CYS532 residue. Furthermore, the quinoline and pyrimidine moieties are intercalated in the space to make a $\pi-\pi$ stacked interaction with PHE583 residue. There is the formation of one halogen bond between the chlorine atom attached to the benzene ring and ILE527. Additionally, the higher binding score of compound 5 might

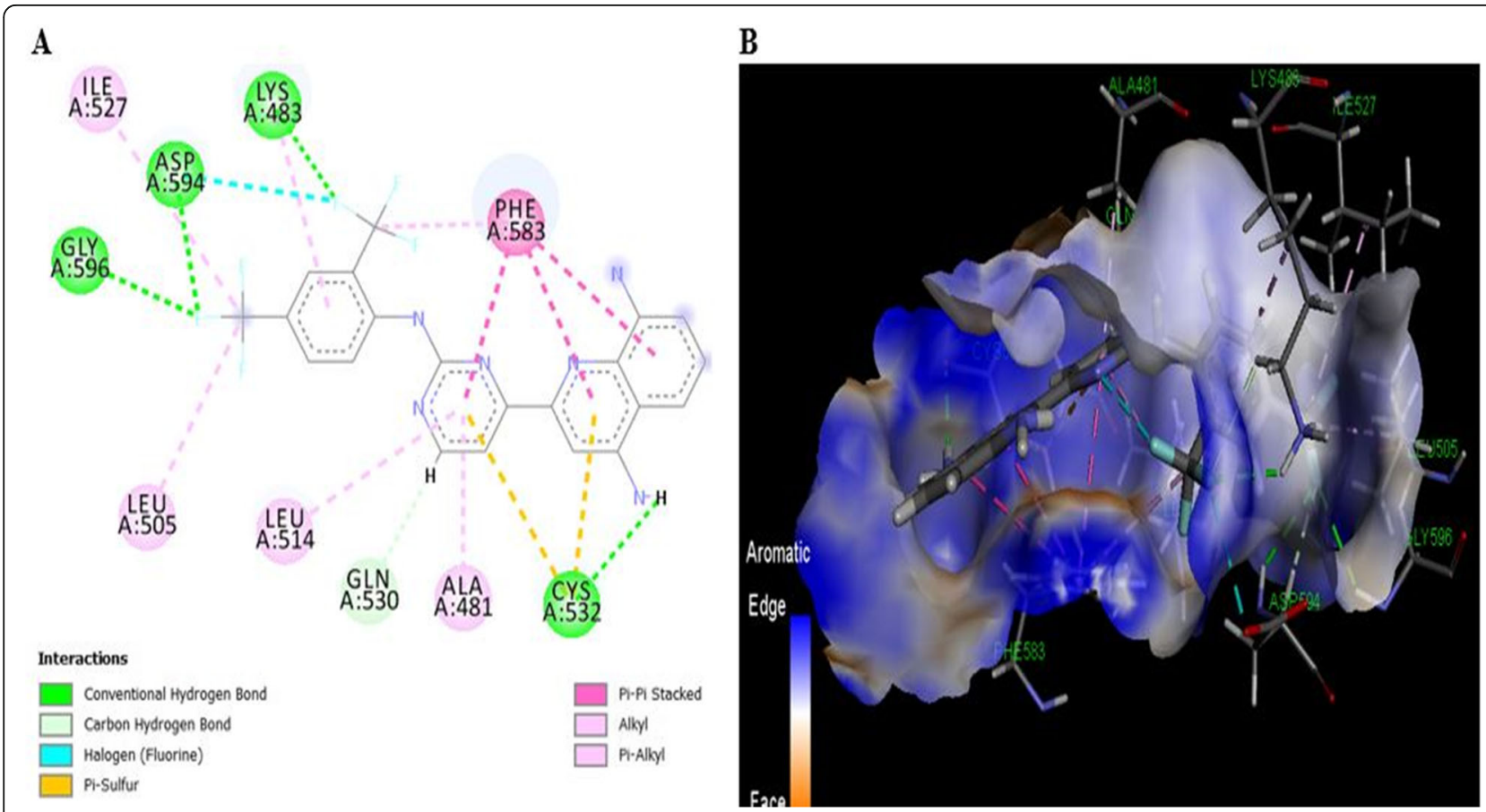

Fig. 3 a $2 D$ diagram for the interaction of compound 9 with V600E-BRAF. b 3D view of the compound 9 in the binding site of V600E-BRAF 


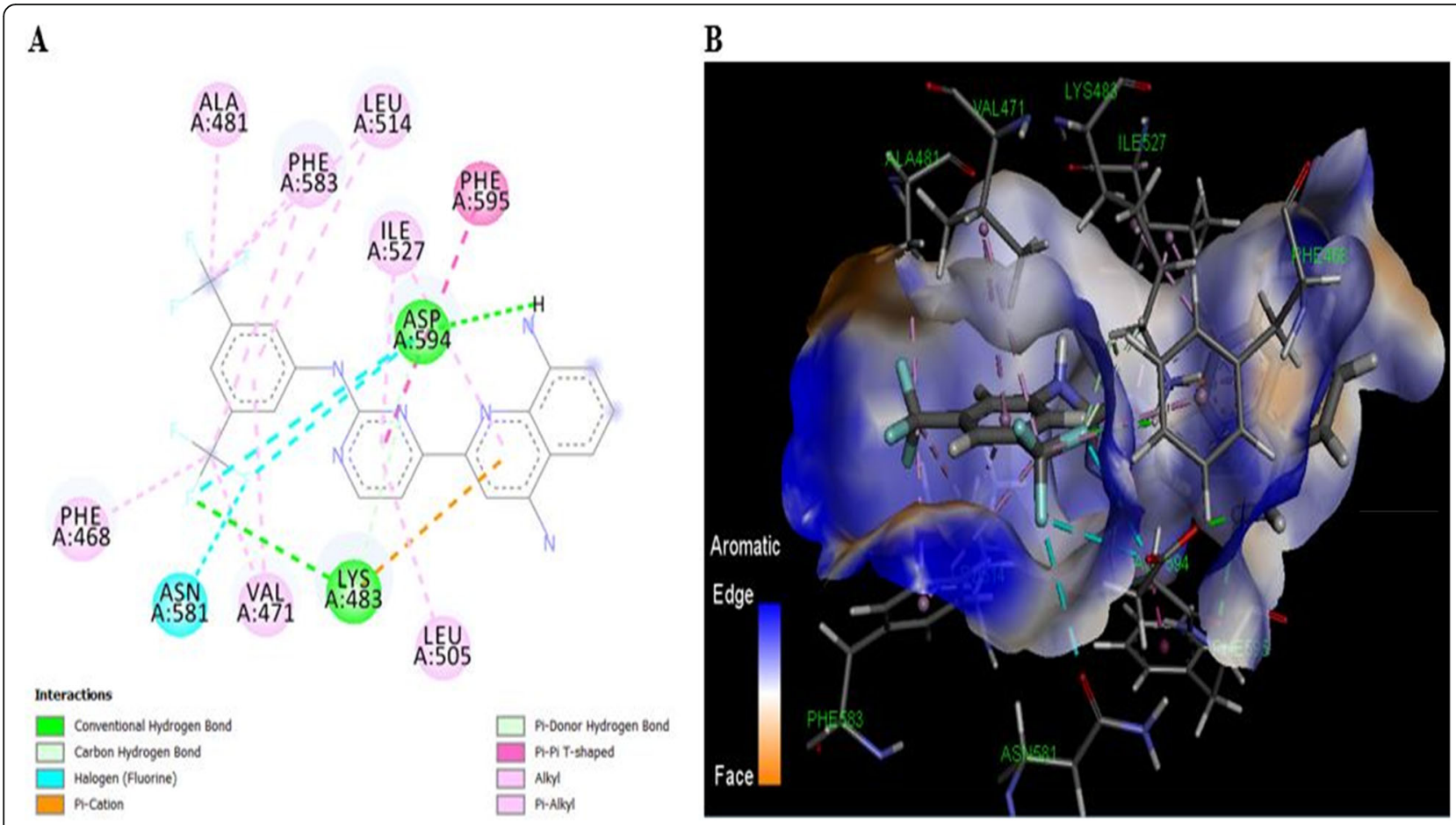

Fig. 4 a $2 D$ diagram for the interaction of compound 10 with V600E-BRAF. b 3D diagram of compound 10 in the binding site of V600E-BRAF

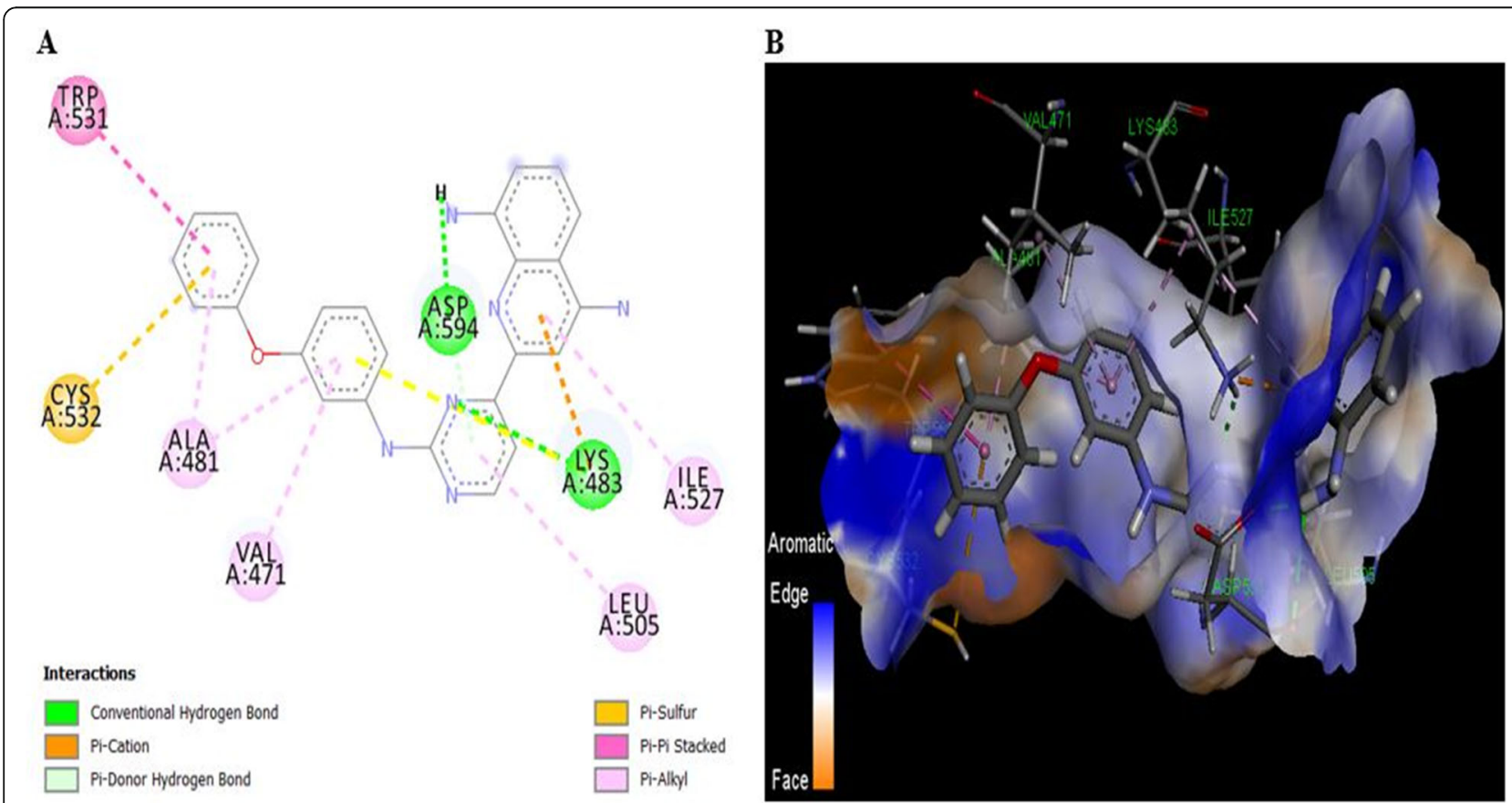

Fig. 5 a 2D diagram for the interaction of compound 11 with V600E-BRAF. b 3D diagram of compound 11 in the binding site of V600E-BRAF 


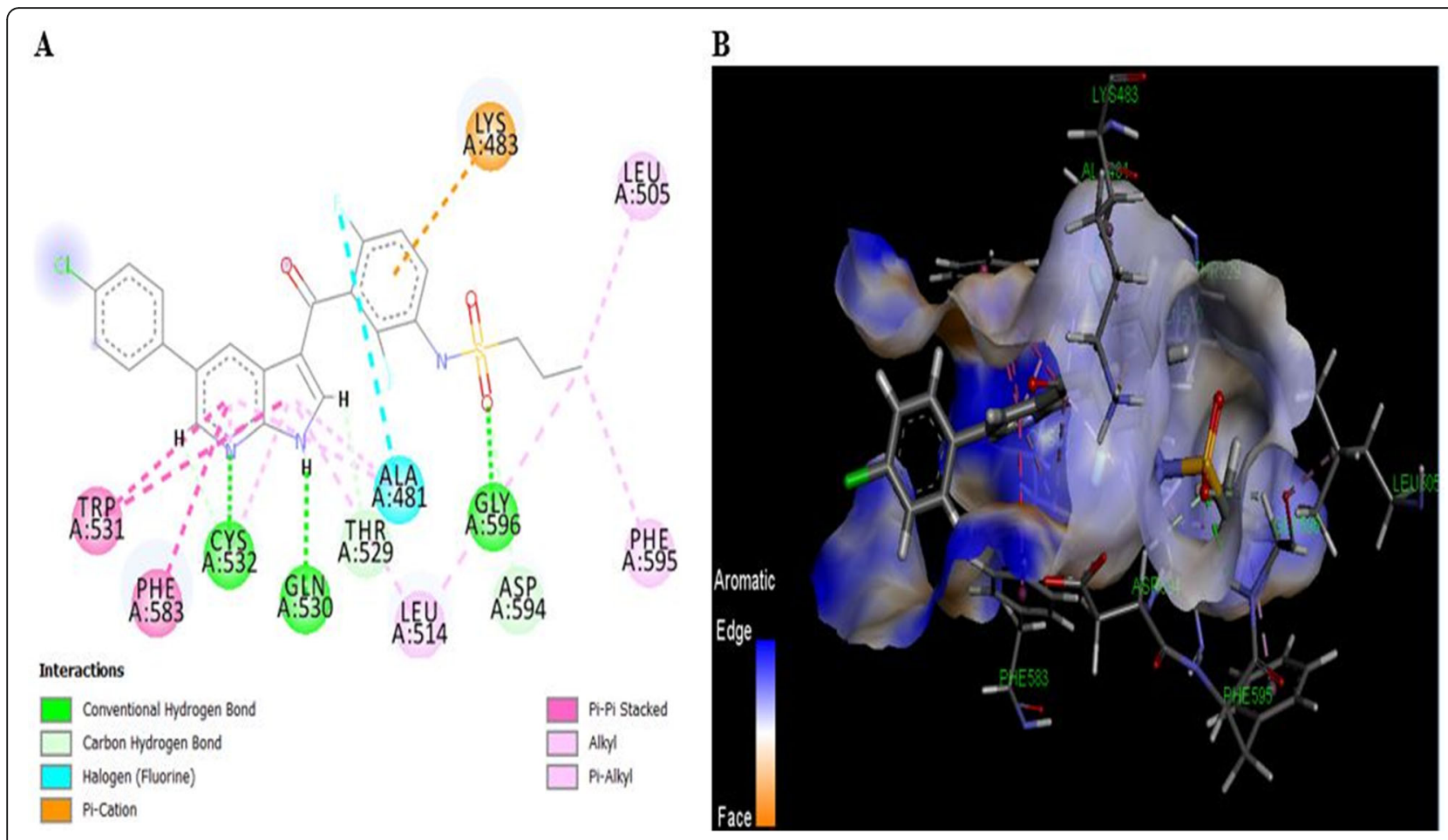

Fig. 6 a 2D diagram for the interaction of vem with V600E-BRAF. b 3D diagram of vem in the binding site of V600E-BRAF

further be accounted for by some other weak interactions, like alkyl with ALA481, ILE527, and LYS483; $\pi-$ alkyl interaction with ALA481, LEU514, CYS532, LYS483, and LEU514; and lastly $\pi$-cation interaction with LYS483. The protein surface model presented in Fig. $1 \mathrm{~b}$ showed that compound 5 has a stable shape complementarity with the ATP-binding cavity of V600EBRAF and the identified types of interactions may contribute to explain its excellent binding scores.

Compound 9 docked into the active site of V600EBRAF kinase (Fig. 3) showed better Rerank score than vemurafenib (Table 2), indicating that it has bound in the active site of one of the protomers in the protein dimer through the formation of four conventional Hbond with LYS483, ASP594, GLY596, and CYS532, respectively. One of the Hbond occurred between the nitrogen atom of an amino group connected with

Table 3 Predicted drug-likeness based on the Lipinski, Ghose, Veber, Egan, and Muegge rules and synthetic accessibility of the selected compounds

\begin{tabular}{lllllll}
\hline SN & Lipinski & Ghose & Veber & Egan & Muegge & Synthetic accessibility \\
\hline 5 & 0 & 1 & 0 & 1 & 0 & 2.91 \\
9 & 0 & 1 & 0 & 1 & 0 & 3.13 \\
10 & 0 & 1 & 0 & 1 & 0 & 3.06 \\
11 & 0 & 0 & 0 & 0 & 0 & 3.2 \\
Vem. & 0 & 2 & 0 & 1 & 0 & 3.38 \\
\hline
\end{tabular}

quinoline skeleton and CYS532, and the others were also formed between the fluorine atoms of the two trifluoromethyl substituents attached to the benzene ring with ASP594, GLY596, and LYS483 residues respectively. Three carbon-Hbond were also observed with LYS483, ASP594, and GLN530 residues, respectively, this might be the reason for the better E-Hbond $(-6.156)$ shown by the complex. Moreover, there was one arene $\pi-\pi$ interaction between the binding site and the ligand with PHE583, which occur due to the intercalation of the benzene ring (Fig. 3). There is a formation of one halogen bond between the fluorine atom of the trifluoromethyl substituent and ASP594. There is however additional $\pi$-alkyl interaction with four residues (PHE583, ALA481, LEU514, and LYS483). The results of this molecular docking study can support the postulation that our active compound may inhibit the growth of melanoma cell lines through inhibition of V600E-BRAF kinase, similar to vemurafenib (Fig. 6).

The complex structure of the docked compound 10 with the receptor is shown in Fig. 4. It has the Rerank score of - 129.661 as presented in Table 2; this indicates the feasibility of good interactions that exist between this compound and the receptor. There were three conventional hydrogen bondings present between the compound and receptor: LYS483 and ASP594 (2) residues between the nitrogen atom of an amino group connected with the quinoline skeleton and the fluorine atom 
Table 4 Predicted ADMET properties of the selected compounds

\begin{tabular}{|c|c|c|c|c|c|c|c|c|}
\hline SN & Gl absorption & BBB permeant & Bioavailability score & CYP- & e/inhi & & & \\
\hline 5 & Low & No & 0.55 & $3 \mathrm{~A} 4$ & $1 \mathrm{~A} 2$ & $2 \mathrm{C} 19$ & $2 C 9$ & $2 \mathrm{D} 6$ \\
\hline 9 & Low & No & 0.55 & Yes & Yes & Yes & No & Yes \\
\hline 10 & Low & No & 0.55 & Yes & Yes & Yes & No & Yes \\
\hline 11 & Low & No & 0.55 & Yes & Yes & Yes & No & Yes \\
\hline Vem. & Low & No & 0.55 & Yes & Yes & Yes & No & Yes \\
\hline
\end{tabular}

Gl gastrointestinal system, BBB blood-brain barrier, CYP cytochrome P

of the trifluoromethyl substituent as presented Fig. 3. Four carbon-H-bond with LYS483 (3) and ASP594 were also observed. There is however formation of two halogen bonds with ASP594 and ASN581 (Fig. 3). The stability of the complex might be associated with an extra, seven $\pi-$ alkyl interactions (PHE468, PHE583 (2), LYS483, ILE527 (2), LEU505, VAL471, and LEU514 residues respectively), and also one $\pi-\pi$ interaction with PHE595.

Figure 5 presented the docked structure of compound 11 with the receptor. It gives a good Rerank score of 140.478 as shown in Table 2; this showed the feasibility of stable interaction between this compound and the receptor. There were three (3) conventional hydrogen bonding identified between this compound and V600EBRAF; LYS483 and ASP594 (2) and three carbon-Hbonds interaction with ASP594. The $\pi$-sulfur interaction was established between a ring (benzene) and CYS532 residue in a similar way to vemurafenib (Fig. 6). The benzene ring moiety has intercalated in the space to create a $\pi-\pi$ stacked interaction with TRP531 residue similar to vemurafenib (Fig. 5). The stability of the complex may be related to an extra, $\pi$-alkyl type of interactions with LYS483, ILE527, LEU505, VAL471, ALA481, LYS483, and ALA481 residues, respectively.

In general, the level of anti-proliferative activities of the studied compounds against the A375P human melanoma cell line as observed from the experiment [27], in which V600EB-RAF kinase is highly expressed [5], and the molecular docking results in this research corroborate well with each other. On performing molecular docking of these compounds into the ATP binding site of V600E-B-RAF kinase showed analogous binding mode to the known V600E-B-RAF kinase inhibitor (vemurafenib). Additionally, the research revealed that hydrogen bonding is the major force controlling the interactions that exist between the docked compound and the protein target, and also the interaction energy of the compounds increases with the increase in the number of the hydrogen bonds [36, 37]. It could be observed that in the conventional hydrogen bonding identified with some of the selected compounds, the number of amino acids involved was found to be better compared to vemurafenib as shown in Figs. 2, 3, 4, 5, and 6 respectively), and there are high similarities. This might acquaint the more reliable binding scores of the chosen compounds for V600E-BRAF. Hence, these compounds may inhibit the growth of melanoma cell lines through inhibition of V600E-BRAF similar to vemurafenib as evident from the molecular docking results.

Furthermore, to guarantee that the selected compounds are the novel drugs, we utilized the drug-likeness and pharmacokinetic ADMET features with vemurafenib as the reference. From the results presented in Table 3, it can be observed that all the selected compounds respect all the drug-likeness rules as none violates more than one criterion set on each rule compared to vemurafenib which violates two in Ghose rule. Moreover, the selected compounds were also assessed for their synthetic accessibility, checking on a scale from 1 (very simple to synthesize) to 10 (very hard and complex to synthesize). The synthetic accessibility for all selected compounds is nearly 3 (Table 3), and therefore, they are easy to synthesize.

The forecasts for the blood-brain barrier (BBB) permeation and passive human gastrointestinal absorption (HIA) both are also very important. As can be observed from Table 4 that all the selected compounds displayed low GI-absorption, which exhibits good absorbance in the human intestine and none hold the $\mathrm{BBB}$ permeant. Also, metabolism shows the chemical biotransformation of a drug by the body. Thus, drugs produce certain metabolites, which may have distinct physicochemical and pharmacological characteristics. It is expected to study the metabolism of drugs and drug-drug interactions [38]. Cytochrome P (CYP) performs a significant role in drug metabolism because the main liver enzyme system is included in phase-1 metabolism (oxidation), as was the case of this research. To date, 17 CYP families have been identified in humans, though only CYP1, CYP2, CYP3, and CYP4 are associated with drug metabolism, with CYP (1A2, 2C9, 2C19, 2D6, and 3A4) being responsible for the biotransformation of more than about $90 \%$ of the drugs undergoing phase I metabolism [38, 39]. Furthermore, cytochrome CYP3A4 inhibition is the most essential phenomenon in this research [40]. All the selected compounds were determined to be the substrate of CYP3A4 and the inhibitor of CYP3A4. According to these results, it can be concluded that these compounds can be used as V600E-BRAF inhibitors and drugs against melanoma cancer in the future. 


\section{Conclusion}

V600E-BRAF is an essential and attractive therapeutic receptor in melanoma and other types of cancer. However, the acquired resistance to vemurafenib to this target and side effects of some other drugs in many events have been reported. Thus, to further examine the antiproliferative potential of V600E-BRAF inhibitors, we employed docking virtual screening combined with an in silico ADMET evaluations and drug-likeness to screen a sequence of some 4-(quinolin-2-yl)pyrimidin-2-amine derivatives. A total of four analogs of 4-(quinolin-2yl)pyrimidin-2-amine derivatives $(5,9,10$, and 11) revealed favorable interaction and better binding scores than vemurafenib, showing common molecular interaction with CYS532, ASP594, GLY596, TRP531, and PHE583 residues of V600E-BRAF. Furthermore, the compounds utilized in this research do not violate the drug-likeness rules to qualify as orally active drugs, and the ADMET evaluation reveals that they are pharmacologically active. These could be likely exploited as lead molecules with enhanced pharmacological properties.

\section{Abbreviations}

DFT: Density functional theory; MVD: Molegro Virtual Docker; ADME T: Absorption, distribution, metabolism, excretion, and toxicity; HBD: Hydrogen bond donor; HBA: Hydrogen bond acceptor

\section{Acknowledgements}

The authors acknowledge the Ahmadu Bello University, Zaria-Nigeria, for the technical support and all the members of the Physical and Theoretical Chemistry research group for their kind advice and encouragement.

\section{Authors' contributions}

AU designed the study. ABU carried out docking simulation, ADMET, and drug-likeness predictions, and drafted the manuscript. SU and GAS participated in designing the study and edited the manuscript. All authors read and approved the final manuscript.

\section{Funding}

Not applicable.

\section{Availability of data and materials}

Data and material are available upon request.

Ethics approval and consent to participate

Not applicable.

\section{Consent for publication}

Not applicable.

\section{Competing interests}

The authors declare that they have no competing interests.

Received: 12 May 2020 Accepted: 17 August 2020

Published online: 21 September 2020

\section{References}

1. Smith RA, Dumas J, Adnane L, Wilhelm SM (2006) Recent advances in the research and development of RAF kinase inhibitors. Curr Top Med Chem 6(11):1071-1089

2. Williams TE, Subramanian S, Verhagen J, McBride CM, Costales A, Sung L, Antonios-McCrea W, McKenna M, Louie AK, Ramurthy S (2015) Discovery of RAF265: a potent mut-B-RAF inhibitor for the treatment of metastatic melanoma. ACS Med Chem Lett 6(9):961-965
3. Li Z, Jiang J-D, Kong W-J (2014) Berberine up-regulates hepatic low-density lipoprotein receptor through Ras-independent but AMP-activated protein kinase-dependent Raf-1 activation. Biol Pharm Bull 37(11):1766-1775

4. Holderfield M, Deuker MM, McCormick F, McMahon M (2014) Targeting RAF kinases for cancer therapy: BRAF-mutated melanoma and beyond. Nat Rev Cancer 14(7):455-467

5. Villanueva J, Vultur A, Lee JT, Somasundaram R, Fukunaga-Kalabis M, Cipolla AK, Wubbenhorst B, Xu X, Gimotty PA, Kee D (2010) Acquired resistance to BRAF inhibitors mediated by a RAF kinase switch in melanoma can be overcome by cotargeting MEK and IGF-1R/PI3K. Cancer Cell 18(6):683-695

6. Luo C, Xie P, Marmorstein R (2008) Identification of BRAF inhibitors through in silico screening. J Med Chem 51(19):6121-6127

7. Uehling DE, Harris PA (2015) Recent progress on MAP kinase pathway inhibitors. Bioorg Med Chem Lett 25(19):4047-4056

8. Menzies AM, Haydu LE, Visintin L, Carlino MS, Howle JR, Thompson JF, Kefford RF, Scolyer RA, Long GV (2012) Distinguishing clinicopathologic features of patients with V600E and V600K BRAF-mutant metastatic melanoma. Clin Cancer Res 18(12):3242-3249

9. Yokota T, Ura T, Shibata N, Takahari D, Shitara K, Nomura M, Kondo C, Mizota A Utsunomiya S, Muro K (2011) BRAF mutation is a powerful prognostic factor in advanced and recurrent colorectal cancer. Br J Cancer 104(5):856-862

10. Fransén $K$, Klintenäs $M$, Österström A, Dimberg J, Monstein $\mathrm{H}$-J, Söderkvist $P$ (2004) Mutation analysis of the BRAF, ARAF and RAF-1 genes in human colorectal adenocarcinomas. Carcinogenesis 25(4):527-533

11. Agrawal N, Akbani R, Aksoy BA, Ally A, Arachchi H, Asa SL, Auman JT, Balasundaram M, Balu S, Baylin SB (2014) Integrated genomic characterization of papillary thyroid carcinoma. Cell 159(3):676-690

12. Brastianos PK, Taylor-Weiner A, Manley PE, Jones RT, Dias-Santagata D, Thorner AR, Lawrence MS, Rodriguez FJ, Bernardo LA, Schubert L (2014) Exome sequencing identifies BRAF mutations in papillary craniopharyngiomas. Nat Genet 46(2):161-165

13. Fiskus W, Mitsiades N (2016) B-Raf inhibition in the clinic: present and future. Annu Rev Med 67:29-43

14. Dienstmann R, Tabernero J (2011) BRAF as a target for cancer therapy. Anticancer Agents Med Chem 11(3):285-295

15. Finn L, Markovic SN, Joseph RW (2012) Therapy for metastatic melanoma: the past, present, and future. BMC Med 10(1):23

16. Murray CW, Rees DC (2016) Opportunity knocks: organic chemistry for fragment-based drug discovery (FBDD). Angew Chem Int Ed 55(2):488-492

17. Jang S, Atkins M (2014) Treatment of BRAF-mutant melanoma: the role of vemurafenib and other therapies. Clin Pharmacol Ther 95(1):24-31

18. Wilhelm S, Carter C, Lynch M, Lowinger T, Dumas J, Smith RA, Schwartz B, Simantov R, Kelley S (2006) Discovery and development of sorafenib: a multikinase inhibitor for treating cancer. Nat Rev Drug Discov 5(10):835-844

19. Chapman PB, Hauschild A, Robert C, Haanen JB, Ascierto P, Larkin J, Dummer R, Garbe C, Testori A, Maio M (2011) Improved survival with vemurafenib in melanoma with BRAF V600E mutation. N Engl J Med 364(26):2507-2516

20. Zhan Y, Dahabieh MS, Rajakumar A, Dobocan MC, M'Boutchou M-N, Goncalves C, Lucy SL, Pettersson F, Topisirovic I, van Kempen L (2015) The role of elF4E in response and acquired resistance to vemurafenib in melanoma. J Invest Dermatol 135(5):1368-1376

21. Liu F, Cao J, Wu J, Sullivan K, Shen J, Ryu B, Xu Z, Wei W, Cui R (2013) Stat3targeted therapies overcome the acquired resistance to vemurafenib in melanomas. J Invest Dermatol 133(8):2041-2049

22. Martinez-Garcia M, Banerji U, Albanell J, Bahleda R, Dolly S, Kraeber-Bodéré F, Rojo F, Routier E, Guarin E, Xu Z-X (2012) First-in-human, phase I doseescalation study of the safety, pharmacokinetics, and pharmacodynamics of RO5126766, a first-in-class dual MEK/RAF inhibitor in patients with solid tumors. Clin Cancer Res 18(17):4806-4819

23. Helvind NM, Hölmich LR, Smith S, Glud M, Andersen KK, Dalton SO, Drzewiecki KT (2015) Incidence of in situ and invasive melanoma in Denmark from 1985 through 2012: a national database study of 24059 melanoma cases. JAMA Dermatol 151(10):1087-1095

24. Barbaric J, Sekerija M, Agius D, Coza D, Dimitrova N, Demetriou A, Diba CS, Eser S, Gavric Z, Primic-Zakelj M (2016) Disparities in melanoma incidence and mortality in South-Eastern Europe: increasing incidence and divergent mortality patterns. Is progress around the corner? Eur J Cancer 55:47-55

25. Cheng T, Li Q, Zhou Z, Wang Y, Bryant SH (2012) Structure-based virtual screening for drug discovery: a problem-centric review. AAPS J 14(1):133-141 
26. Schmidt T, Bergner A, Schwede T (2014) Modelling three-dimensional protein structures for applications in drug design. Drug Discov Today 19(7):890-897

27. Lee JA, Roh EJ, Oh C-H, Lee SH, Sim T, Kim JS, Yoo KH (2015) Synthesis of quinolinylaminopyrimidines and quinazolinylmethylaminopyrimidines with antiproliferative activity against melanoma cell line. J Enzyme Inhib Med Chem 30(4):607-614

28. Dhillon AS, Hagan S, Rath O, Kolch W (2007) MAP kinase signalling pathways in cancer. Oncogene 26(22):3279

29. Ulrich B, Norman L (1982) Molecular mechanics (ACS monograph 177). Am Chem Soc, Washington, DC

30. Molegro A (2011) MVD 5.0 Molegro Virtual Docker, A CLC Bio Company

31. Brose MS, Volpe P, Feldman M, Kumar M, Rishi I, Gerrero R, Einhorn E, Herlyn M, Minna J, Nicholson A (2002) BRAF and RAS mutations in human lung cancer and melanoma. Cancer Res 62(23):6997-7000

32. Bollag G, Hirth P, Tsai J, Zhang J, Ibrahim PN, Cho H, Spevak W, Zhang C, Zhang Y, Habets G (2010) Clinical efficacy of a RAF inhibitor needs broad target blockade in BRAF-mutant melanoma. Nature 467(7315):596

33. Choi W-K, El-Gamal Ml, Choi HS, Baek D, Oh C-H (2011) New diarylureas and diarylamides containing 1, 3, 4-triarylpyrazole scaffold: synthesis, antiproliferative evaluation against melanoma cell lines, ERK kinase inhibition, and molecular docking studies. Eur J Med Chem 46(12):5754-5762

34. Thomsen R, Christensen MH (2006) MolDock: a new technique for highaccuracy molecular docking. J Med Chem 49(11):3315-3321

35. Martinez-Mayorga K, Madariaga-Mazon A, Medina-Franco JL, Maggiora G (2020) The impact of chemoinformatics on drug discovery in the pharmaceutical industry. Expert Opin Drug Discov 15(3):293-306

36. Adedirin O, Uzairu A, Shallangwa GA, Abechi SE (2018) Optimization of the anticonvulsant activity of 2-acetamido-N-benzyl-2-(5-methylfuran-2-yl) acetamide using QSAR modeling and molecular docking techniques. BeniSuef Univ J Basic Appl Sci 7(4):430-440

37. Umar BA, Uzairu A, Shallangwa GA, Uba S (2019) Rational drug design of potent V600E-BRAF kinase inhibitors through molecular docking simulation. J Eng Exact Sci 5(5):0469-0481

38. Kok-Yong S, Lawrence L (2015) In: Ahmed TA (ed) Drug distribution and drug elimination. Basic pharmacokinetic concepts and some clinical applications. InTech, Rijeka, pp 99-116

39. Šrejber M, Navrátilová V, Paloncýová M, Bazgier V, Berka K, Anzenbacher P, Otyepka M (2018) Membrane-attached mammalian cytochromes P450: an overview of the membrane's effects on structure, drug binding, and interactions with redox partners. J Inorg Biochem 183:117-136

40. Thapar MM, Ashton M, Lindegårdh N, Bergqvist Y, Nivelius S, Johansson I, Björkman A (2002) Time-dependent pharmacokinetics and drug metabolism of atovaquone plus proguanil (Malarone) when taken as chemoprophylaxis. Eur J Clin Pharmacol 58(1):19-27

\section{Publisher's Note}

Springer Nature remains neutral with regard to jurisdictional claims in published maps and institutional affiliations.

\section{Submit your manuscript to a SpringerOpen ${ }^{\circ}$ journal and benefit from:}

- Convenient online submission

- Rigorous peer review

- Open access: articles freely available online

- High visibility within the field

- Retaining the copyright to your article

Submit your next manuscript at $\boldsymbol{\nabla}$ springeropen.com 